\title{
Sedimentação atual nas enseadas de Ubatumirim e Picinguaba, região norte de Ubatuba, Estado de São Paulo, Brasil
}

\author{
(Modern sedimentation pattern in Ubatumirim and Picinguaba Bay, northern \\ Ubatuba coastal region, São Paulo State, Brazil)
}

Marcelo Rodrigues; Michel Michaelovitch de Mahiques \& Moysés Gonsalez Tessler

Instituto Oceanográfico da Universidade de São Paulo

(Praça do Oceanográfico, 191, Butantã 05508-900 São Paulo, SP, Brasil)

mrrodrig@usp.br; mahiques@usp.br; mgtessle@usp.br

- Abstract: This work deals with the identification of the bathymetric, sedimentary distribuition, and sedimentary features, as well as with their correlation to hydrodynamic processes which are responsible for the transportation and deposition of particulate materials in Ubatumirim and Picinguaba bays and in the adjacent inner shelf. The methodology comprised the batthymetric characterization, 77 bottom surface sampling and the measurements of temperature and salinity profiles. Results showed the dominance of fine and very fine sands, and secondarily, the existence of NNW-SSE elongated coarse and medium sand features. These features are related to relict sediments. The oceanographic structure shows an anti-clockwise circulation in the bays, with an opposite direction for the longshore currents, which demonstrate rip cell circulation in opposite direction along the coastline This pattern causes the transport of fluvial sediments to the opposite sides of the beaches. The sediment transport and generation of sedimentary features could be associated to the passage of cold fronts over the area.

- Resumo: Os objetivos deste trabalho consistem na identificação das características sedimentológicas e batimétricas da superfície de fundo e sua correlação com os agentes dinâmicos, que visando caracterizar os processos sedimentares atuantes nas enseadas de Ubatumirim e Picinguaba e na plataforma interna adjacente. Os trabalhos realizados consistiram na caracterização da batimetria de detalhe da área, na coleta e análise de 77 amostras de sedimentos de superfície de fundo, em levantamentos bimestrais de perfis termossalinométricos e análise de fotos aéreas. Os resultados obtidos demonstram o predomínio de sedimentos compostos de areias finas e muito finas e, secundariamente, por areias médias e grossas, que compõem feições manchas e feições alongadas, orientadas segundo NNW-SSE. Estas feições representam variações marcantes na composição dos sedimentos, possivelmente associadas a sedimentos palimpsestos. A estrutura oceanográfica da área mostra um padrão de circulação no interior das enseadas predominantemente no sentido anti-horário, com células de circulação junto à linha de costa em sentido oposto, que influenciam o transporte de sedimentos provenientes dos rios que aportam nas praias do interior das enseadas. As velocidades de correntes junto ao fundo, mais efetivas na distribuição sedimentar devem estar associadas aos agentes dinâmicos gerados pela passagem de sistemas frontais.

- Descriptors: Sediment dinamics, Coastal bays, Bottom sediments, Circulation, Oceanography.

- Descritores: Dinâmica sedimentar, Sedimentos de fundo, Oceanografia. 


\section{Introdução}

O litoral sudeste brasileiro, na região compreendida entre o norte do Estado de São Paulo e sul do Rio de Janeiro, configura-se como um ambiente costeiro muito recortado, caracterizado pela ocorrência de planícies costeiras descontínuas e restritas pela proximidade da Serra do Mar, que se projeta, na forma de promontórios de rochas cristalinas, em direção ao Oceano Atlântico, individualizando-as em enseadas de contornos compostos por costões rochosos e praias de bolso, com aporte fluvial incipiente, e com ocorrência de ilhas e parçéis em suas porções interiores, testemunhos isolados da evolução geomorfológica da região

Dentro deste contexto, a região costeira de Ubatuba, no litoral norte de São Paulo, é composta por dois domínios principais. O domínio representado pela Serra do Mar é formado por rochas préCambrianas de várias unidades litológicas, caracterizadas como gnaisses, migmatitos, granulitos e granitos, com forte controle estrutural de orientação preferencial SW-NE. Apresenta relevo do tipo escarpas abruptas e festonadas, com espigões, promontórios e pequenos maciços e morros isolados que avançam para as baixadas, chegando a atingir a linha de costa, individualizando-a em pequenas planícies costeiras, que são características da região (Ponçano et al., 1981). As planícies, que compõem o segundo domínio, são caracterizadas como reduzidas e descontínuas, desenvolvidas sobre um pacote de sedimentos marinhos e continentais Quaternários.

Estudos sobre a sedimentação atual nas enseadas do litoral norte de São Paulo têm revelado uma grande complexidade no comportamento dinâmico e conseqüentemente na resposta sedimentar, resultado dos diferentes aspectos morfodinâmicos condicionantes, presentes neste ambiente. Entre esses pode se citar a condição semiabrigada do interior das enseadas, a presença de ilhas, parcéis e dos próprios costões rochosos que induzem a orientação da circulação das águas e os processos de difração e refração dos trens de ondas. Estas características morfológicas restrigem, segundo Magliocca \& Kutner (1965), o aporte de sedimentos terrígenos do interior dessas enseadas para a plataforma continental adjacente.

Associado a estes condicionantes, a transferência de encrgia dos grandes processos atmosféricos do Atlântico sul para o meio marinho e sua influência nos padrões dinâmicos incidentes na costa sudeste, gera variações temporais nas condições meteorológicas do litoral sudeste, que são determinadas pelo balanço entre massas de ar tropical e polar e pela frequiência das perturbações transientes (Occhipinti, 1963). Essas variações estão relacionadas à passagem dos sistemas frontais provenientes das regiões polares a sul, quo avançam rumo ao norte passando pela costa sul americana, atingindo com frequiência a região sudeste brasileira.

Segundo Tessler (1988) estas variações são responsáveis pela orientação dos trens de ondas incidentes sobre o litoral, sendo predominante os trens provenientes de nordeste, associados aos ventos alísios, e os provenientes do quadrante sul, formados com a passagem desses sistemas frontais. A esta última condição estão relacionados os processos mais intensos da dinâmica sedimentar na região.

Em estudos realizados nas enseadas a sul de Ubatuba, Mahiques (1995) observa a ocorrência de padtões de sedimentação distintos, com grande variabilidade espacial dos tipos sedimentológicos. resultados das características fisiográficas e hidrodinâmicas de cada unidade. Em termos hidrodinâmicos, o autor observou a ocorrência de condições dinâmicas para a remobilização de sedimentos arenosos finos durante a passagem de sistemas frontais. Mahiques et cl. (1998). analisando os componentes da fração grossa dos sedimentos, identificou as variações no gradiente de energia dos agentes dinâmicos nos sedimentos de fundo das enseadas, em relação à distribuição espacial, evidenciando que as diferenças cntre as distintas enseadas da região são fortemente condicionadas por ação de ondas e orientação das desembocaduras.

As enseadas de Ubatumirim e Picinguaba apresentam suas desembocaduras voltadas para sul-sudeste, configurando um laboratório perfeito para a identificação dos efeitos diretos dos sistemas frontais na sedimentação atual desse tipo de ambiente.

\section{Área de estudo e objetivos do trabalho}

No litoral norte do Estado de São Paulo. especificamente na região norte de Ubatuba, duas unidades fisiográficas, caracterizadas pelas enseadas de Ubatumirim c Picinguaba, constituem a área de menor ocupação e atividade antrópica da região, c objeto deste estudo. Esta área, localiza-se entre as latitudes $23^{\circ} 20^{\prime} \mathrm{S}$ e $23^{\circ} 27^{\prime} \mathrm{S}$ e as longitudes $044^{\circ} 51^{\prime} \mathrm{W}$ e $045^{\circ} 01^{\prime} \mathrm{W}$ (Fig. 1). Foi definida a isóbata de 25 metros como o limite dos levantamentos, o qual praticamente coincide com o limite fisiográfico das desembocaduras das enseadas. 


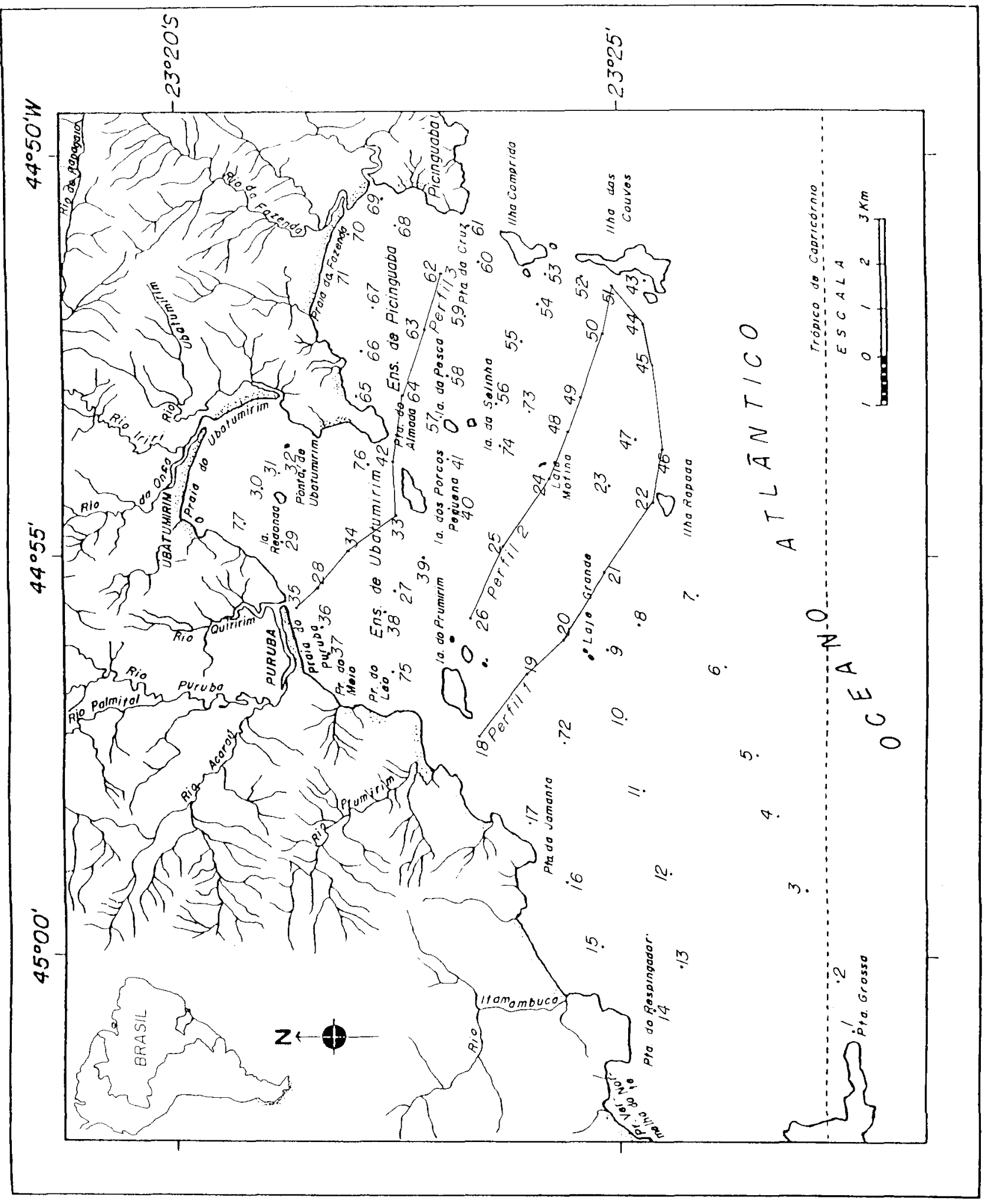

Fig. 1. Localização da área de estudo e disposição das estações de coletas de sedimentos e dos perfis de temperatura e salinidade. 
Rev. bras. de oceanogr., 50(único), 200)?

Os objetivos deste trabalho consistem no reconhecimento dos processos atuantes na sedimentação atual das enseadas de Ubatumirim e Picinguaba. Estas enseadas apresentam desembocaduras voltadas para sul-sudoeste, sofrendo influência direta da ação dinâmica gerada pela passagem dos sistemas frontais. A estas características intrínsecas, que as distinguem das enseadas a sul, acrescenta-se a deficiência de estudos integrados de parâmetros meteorológicos e hidrodinâmicos, associados às características dos sedimentos superficiais de fundo como fator genético e inserido em um contexto de variabilidade temporal.

\section{Material e métodos}

Como base para os estudos, foi realizada a caracterização batimétrica de detalhe da área, através da análise da Folha de Bordo da Diretoria de Hidrografia e Navegação (DHN-MM) FB-1635$002 / 80$, e do traçado de isóbatas em intervalo de um metro, até a profundidade de 25 metros. Analisou-se ainda dois conjuntos de fotos aéreas, de 1973 e de 1977 para identificação do comportamento dos trens de ondas incidentes nas enseadas, seus processos de difração nas porções internas, bem como do ângulo de incidência junto à linha de costa.

Os trabalhos de coleta de dados de campo consistiram inicialmente na coleta de 77 amostras de sedimentos superficiais, utilizando-se um amostrador de fundo do tipo Petersen. O posicionamento das estações de amostragem foi obtido com GPS. As análises granulométricas dos sedimentos coletados foram realizadas segundo as técnicas de peneiramento e pipetagem descritas em Suguio (1973), visando a obtenção das classes e dos parâmetros estatísticos granulométricos segundo Folk \& Ward (1957), além das porcentagens das frações areia e lama.

Foram realizadas várias séries de levantamentos pontuais de temperatura e salinidade, ao longo da coluna d'água, dispostos em três perfis aproximadamente paralelos às desembocaduras das enseadas, cobrindo suas porções externas médias e internas. Esses levantamentos foram realizados bimestralmente, em um total de 8 campanhas realizadas a bordo do Barco de Apoio à Pesquisa Veliger II, do Instituto Oceanográfico da Universidade de São Paulo. Como complemento às informações sobre o comportamento hidrodinâmico do interior das enseadas foram lançados grupos de dez derivadores de fundo do tipo Woodhead (Woodhead \& Lee, 1960, apud Bartolini \& Pranzini, 1977), nas desembocaduras dos rios Puruba, Ubatumirim e Fazenda, em período de maré vazante, para cada etapa. A Figura 1 mostra a localização das estações de coletas de sedimentos e a posição dos perfis de termossalinidade.

\section{Resultados}

\section{Batimetria}

As enseadas de Ubatumirim e Picinguaba apresentam seus limites interiores representados pelas praias de Ubatumirim e Fazenda, respectivamente, orientadas na direção NW-SE, e suas desembocaduras voltadas para Sul-Sudoeste, apresentando configuração aproximadamente retangular. Estas características da área de estudo estão relacionadas com os processos erosivos associados a condicionantes estruturais (foliações, planos de fraturas) das rochas que compõem a Serra do Mar na área, com orientação preferencial para SW-NE.

Segundo Mahiques (1992), tanto a conformação batimétrica das enseadas da região de Ubatuba, como a topografia das áreas emersas adjacentes, seriam indicativos de uma origem ligada à erosão remontante da Serra do Mar e a paleodrenagens desenvolvidas durante o máximo regressivo de 18.000 anos $\mathrm{AP}$, sendo os pontões cristalinos que individualizam as enseadas, bem como as ilhas, lajes e parcéis presentes na área, testemunhos dos interflúvios do passado. A Figura 2 mostra a distribuição das isóbatas das enseadas de Ubatumirim e Picinguaba.

A Enseada de Ubatumirim, apresenta duas porções com características diferenciadas. A porção externa da enseada, a partir do trecho entre a ilha Rapada e a Laje Grande, apresenta isóbatas com espaçamento regular e padrão serrilhado, tendendo a uma disposição em semi-arco. Têm seu comportamento alterado parcialmente por influência da zona de sombra da ilha Rapada e por duas feições semelhantes a canais, que avançam, uma próxima à face oeste da ilha Rapada e outra entre a laje Mofina e a ilha Rapada, até o limite da porção mais interna da enseada, entre as ilhas do Promirim e dos Porcos Pequena.

A partir deste trecho, a disposição das isóbatas em relação à linha de costa se modifica, tanto próximo à Itha do Prumirim, onde ocorre um aumento na declividade da superfície de fundo, como em direção à praia de Puruba, com espaçamento regular, e apresentando, próximo ao limite NE da praia, junto à ponta do Arpoador, uma feição semelhante a um canal, que avança enseada adentro, possivelmente relacionada à dinâmica fluvial do rio Puruba, representativa de um paleocanal formado em períodos de nivel médio do mar mais baixo que o atual. 


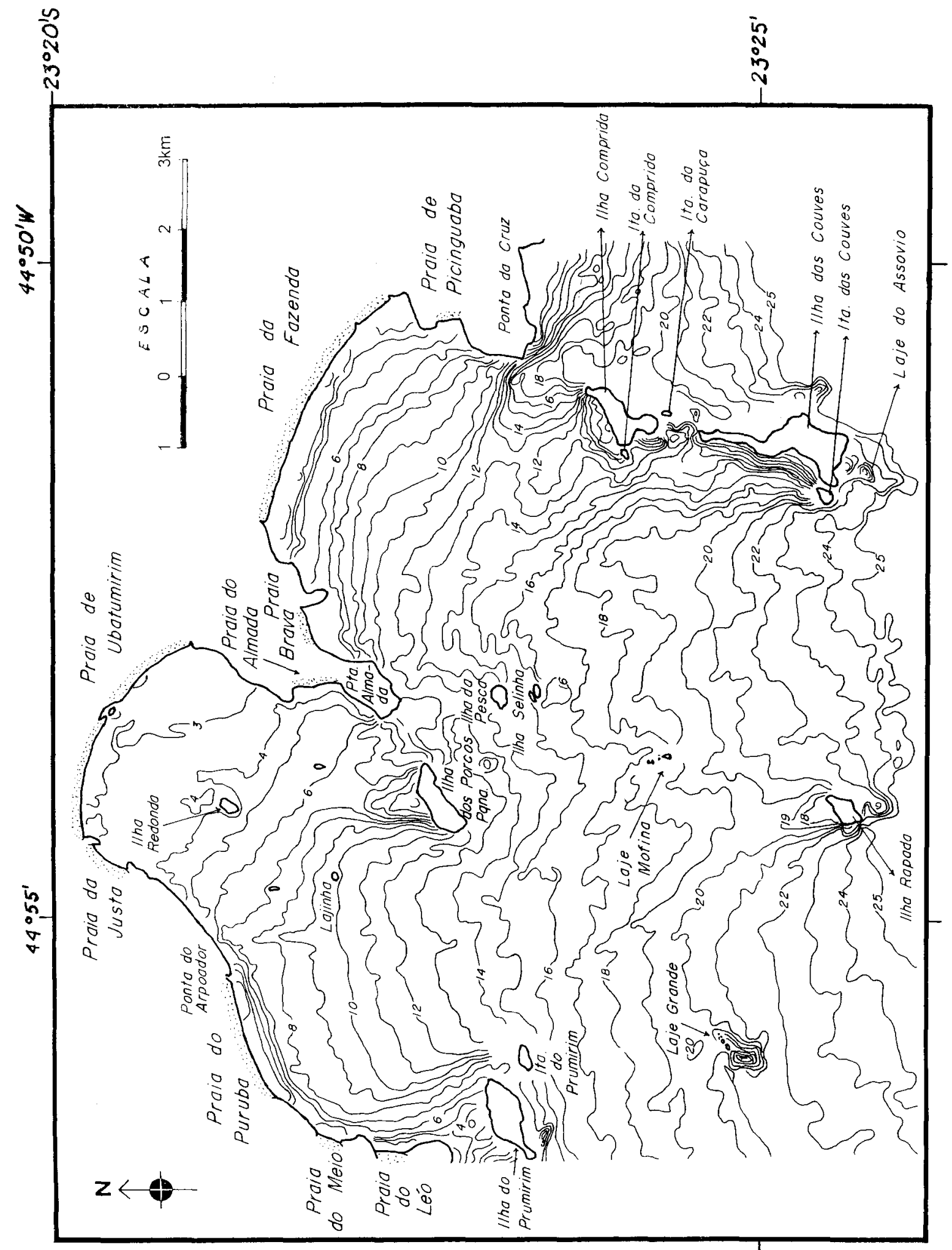

Fig. 2. Mapa batimétrico da área. 
Há, também, alteração na configuração das isóbatas por influência da ilha dos Porcos Pequena e pela própria linha de costa oposta à ilha, passando a orientar-se em direção paralela à Praia de Ubatumirim. Apresentam, a partir deste trecho, um espaçamento crescente, configurando um ambiente de baixa energia, raso e altamente favorável a processos deposicionais, principalmente em sua porção próxima à desembocadura do rio Ubatumirim.

Observa-se na ilha do Prumirim, uma área propícia a processos deposicionais situado entre ela e o continente, semelhante ao estágio inicial de formação de um tômbolo. A Itha dos Porcos Pequena apresenta uma área de franca sedimentação na face voltada para a enseada. inclusive com a formação de praia. Esta, segundo informações locais, migra de posição no decorrer do ano, chegando a desaparecer eventualmente. Não se tem um controle espaçotemporal desse fenômeno, porém há informações de que estas variações estejam associadas a períodos de maior ou menor freqüência de passagem de sistemas atmosféricos frontais.

O canal entre a ilha dos Porcos Pequena e a Ponta do Almada apresenta profundidades maiores junto à ilha e menores nas adjacências dos costões rochosos continentais, indicando o setor preferencial para a circulação de água entre as enseadas.

A região externa da enseada de Ubatumirim, delimitada por um eixo interligando as ilhas do Promirim à Laje Grande, e estendendo-se em sentido SE até a tlha Rapada, caracteriza-se pela maior constância na distribuição das isóbatas, com espaçamento crescente com a profundidade, ocorrendo também algumas feições com formato serrilhado.

A enseada de Picinguaba apresenta, em suas porções mais externas, um padrão irregular de distribuição das isóbatas, sendo condicionadas pela presença de vários parcéis e lajes cristalinas, além de sofrer a influência direta das ilhas das Couves e Comprida que, juntas, formam o maior conjunto deste tipo na área, definindo a maior parte do limite leste desta enseada.

Nesta porção mais externa da enseada observam-se feições indicativas de canal preferencial de circulação de água, que se projeta do trecho entre a laje Mofina e a ilha da Pesca até a região entre a Ilha Rapada e Couves, na desembocadura do sistema.

Junto à Ilha das Couves, as isóbatas infletem, tendendo a orientar-se paralelamente à sua face voltada para o interior da enseada, com o relevo apresentando um aumento da declividade conforme se aproxima da ilha. Nota-se, entretanto, a presença de um cone de sedimentação na face interna da Ilha Comprida, que se prolonga para o interior da enseada, bem marcado pela isóbata de $12 \mathrm{~m}$, situada próximo ao canal entre a Ilha Comprida e o continente.

O canal entre a Ilha Comprida e a Ponta da Cruz apresenta profundidades que atingem em tomo de 19 metros apresentando um do perfil batimétrico assimétrico paralelo ao eixo do canal, com declividade acentuada no sentido das porções externas da enseada.

Próximo a linha de costa, as isóbatas apresentam uma distribuição aproximadamente paralela à praia da Fazenda, com espaçamento regular, porém com maior declividade em relação à área correspondente na enseada de Ubatumirim.

\section{Estrutura Oceanográfica das Enseadas}

Os dados levantados para os meses de março e maio de 1993 apresentam estratificação bem marcada, com valores de temperatura o salinidade indicando entrada de águas mais frias e salinas nas porções orientais das enseadas.

Nos meses de julho e setembro, a estrutura oceanográfica das enseadas apresentou baixas amplitudes nos valores termohalinos, revelando uma tendência à homogeneização, que se inverte no mês de novembro de 1993, com grandes amplitudes térmicas e estratifícação marcante. Deve-se ressaltar. para o mês de julho de 1993, a ocorrência de núcleo composto de águas de baixa temperatura e alta salinidade na porção oeste da enseada de Ubatumirim, em seu perfil mais interno. Esta condição também é observada no mesmo perfíl na enseada de Picinguaba, embora de forma menos cvidente, indicando uma tendência de entrada de água pela porção oeste do sistema, atingindo o interior das enseadas, para este pcríodo.

Durante todo o período acima descrito, ocorreu, de forma geral, uma tendência a um aumento nos valores de salinidade e diminuição na temperatura da água, nas enseadas, como um todo. Esta tendência evolui num crescendo, de março de 1993 para os meses de julho e setembro, atingindo seu máximo na etapa de novembro de 1993, onde as tempcraturas atingiram valores mínimos menores que $17^{\circ} \mathrm{C}$, junto à superfície de fundo, que podem ser relacionadas com a penetração da Água Central do Atlântico Sul (ACAS) na plataforma interna do litoral paulista, segundo modelo proposto por Castro Filho et al. (1987).

$\mathrm{Na}$ etapa de maio de 1994 ocorre uma diminuição na amplitude térmica nas porções internas da cnseada, voltando a apresentar uma estrutura com penetração preferencial de água oceânica pelas porções orientais das enseadas. Essa análise dos perfis de temperatura e salinidade revelou a predominância, ao longo do período amostrado, de 
um padrão geral de circulação de água com sentido anti-horário, para as enseadas estudadas. Os perfis esquemáticos representativos do padrão predominante da circulação interna das enseadas baseado na estrutura termossalinométrica das suas águas estão presentes nas Figuras 3 a 6.

\section{TEMPERATURA $\left({ }^{\circ} \mathrm{C}\right)$ - MARCO $/ 1993$}
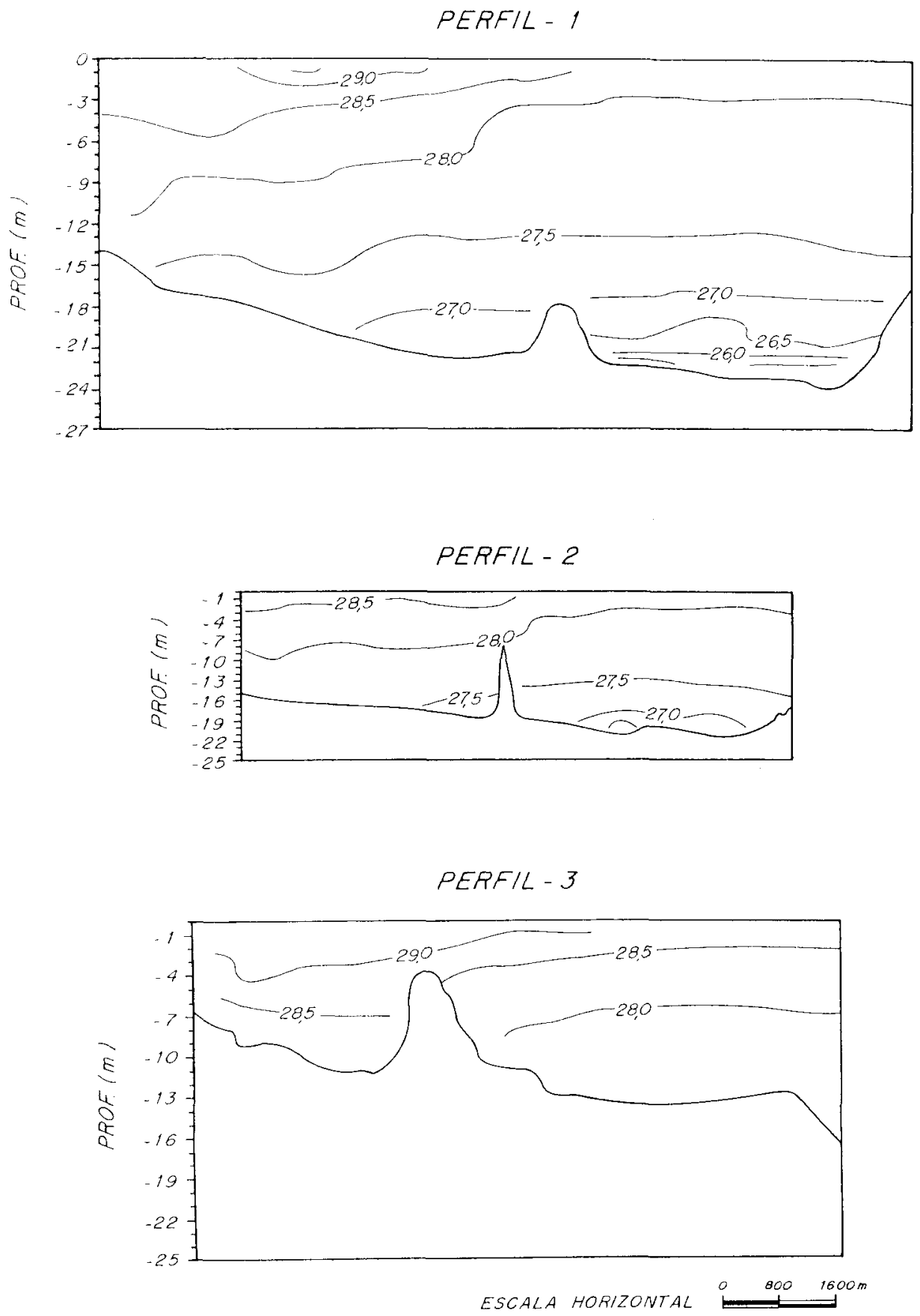

Fig. 3. Perlis de temperatura ("C)/março de 1993. 
SALINIDADE (\%o) - MARCO/1993
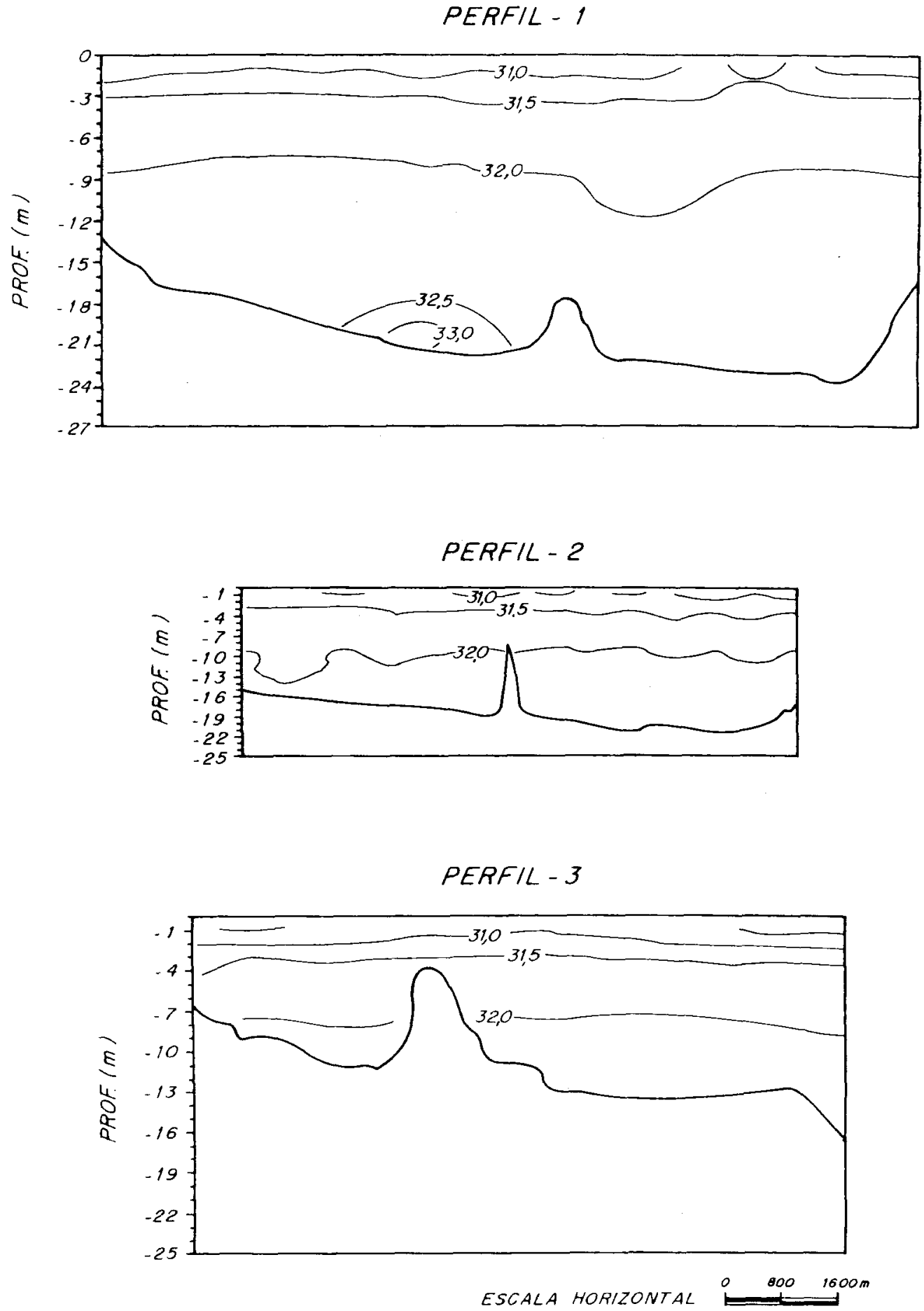

Fig. 4. Perfis de salinidade (\%)/março de 1993. 

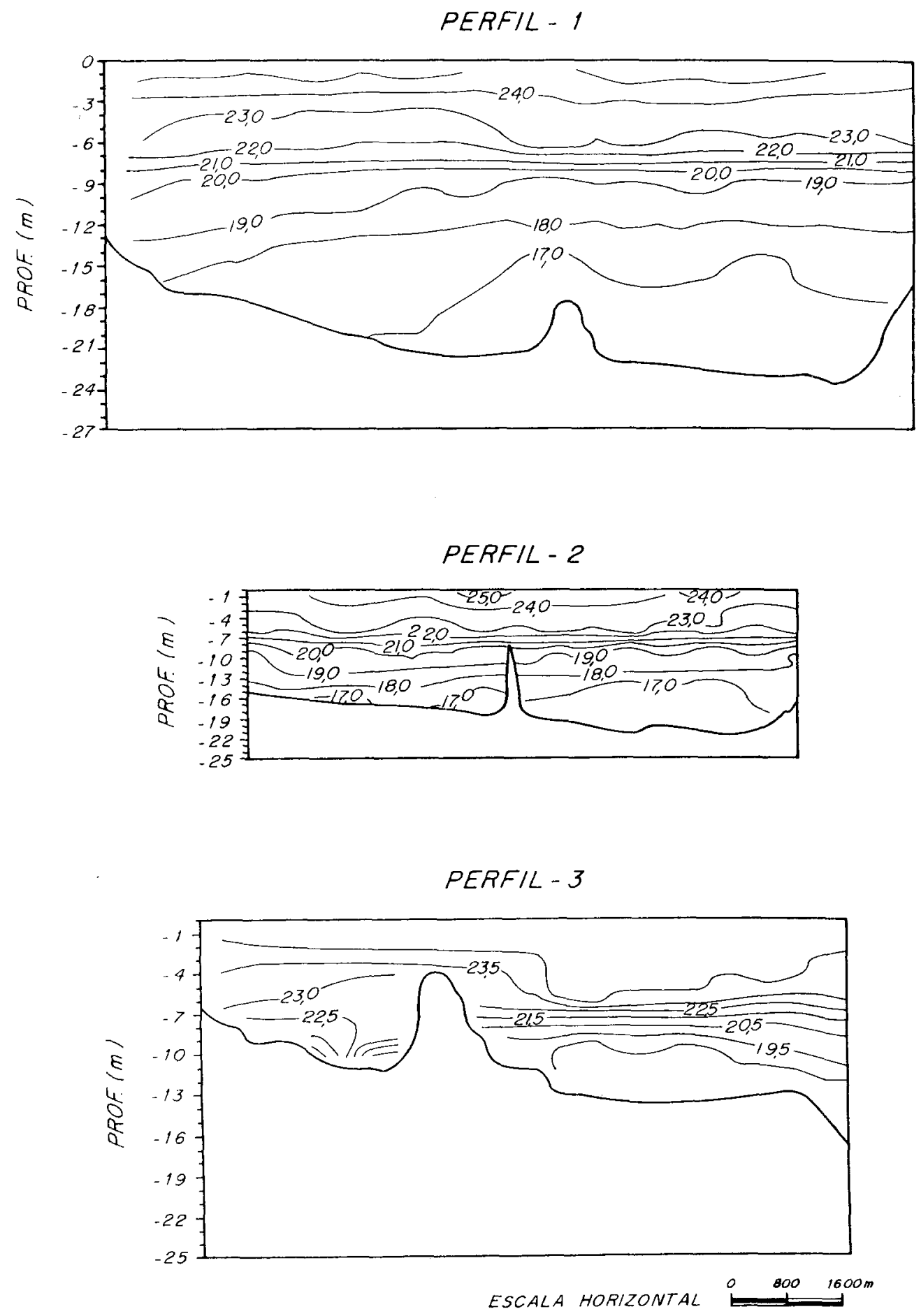

Fig. 5. Perfis de temperatura $\left({ }^{\circ} \mathrm{C}\right) /$ novembro de 1993 


\section{SALINIDADE (\%०) - NOVEMBRO/1993}
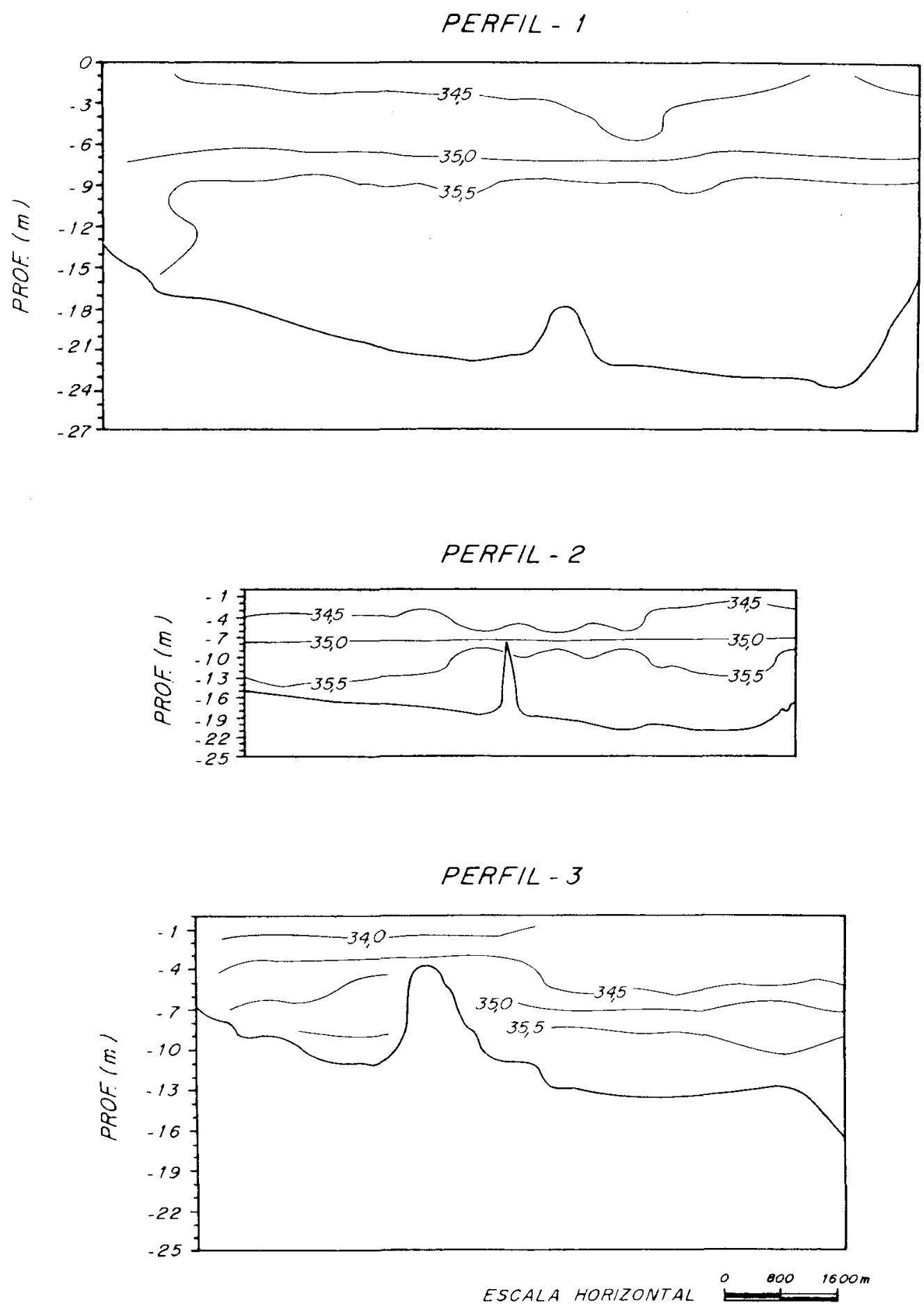

Fig. 6. Perfis de salinidade (\%)/novembro de 1993. 
O estudo sobre circulação de água através do lançamento de corpos de deriva permitiu a obtenção de informações qualitativas sobre o comportamento das correntes de fundo das enseadas. Com relação ao período de permanência dos corpos de deriva, Funtado et al. (1987)* considera que longas permanências são sugestivas de trajetórias não retilineas, para áreas costeiras. Devido à complexidade das características morfodinâmicas das enseadas de Ubatumirim e Picinguaba, considerou-se as trajetórias dos derivadores de fundo como inferidas.

O comportamento dos derivadores, lançados das desembocaduras dos rios Puruba Ubatumirim e Fazenda mostra uma tendência comum nos três pontos de lançamento. Eles são transportados inicialmente, em sentido coerente com a deriva litorânea e com o crescimento dos esporões praiais sendo, entretanto, recupcrados no extremo oposto e/ou ao longo da respectiva praia e mesmo próximo às desembocaduras dos rios, após horas e/ou dias decorridos do lançamento.

O comportamento inicial da trajetória dos derivadores de fundo, a partir do lançamento nas desembocaduras dos rios, foi acompanhado até a profundidade de cerca de 1,5 metros de profundidade, de forma a confirmar o sentido do deslocamento inicial coerente com o sentido em que as águas fluviais tomam, influenciadas pela corrente de deriva litorânea. Na praia da Fazenda porém, a recuperação ocorre sempre nas proximidades da desembocadura do rio, e eventualmente a 400 metros de distância da mesma, geralmente num período inferior a 24 horas.

O comportamento dos trens de ondas provenientes da região da plataforma continental interna ao adentrar para o interior nas enseadas, a partir da análise de aerofotos, mostra uma grande variação nas direções e sentidos de deslocamento, alterando-se freqüentemente à medida que se desloca para o interior, em função da presença de ilhas e da própria fisiografia das enseadas.

Com relação à enseada de Ubatumirim, a partir da ilha do Promirim ocorre uma difração dos trens de ondas, incidindo de SSE até a praia do Puruba. Nas porções mais internas da enseada, foi possivel observar um padrão de difração bem marcado, gerado pela llha Redonda, onde há a formação de uma área de deposição na face interna. $\mathrm{Na}$ praia de Ubatumirim os trens de ondas incidem,

(*) Furtado, V. V.; Eichler, B. B.: Sanches, T. M. \& Tessfer. M. G 1987. Consideraçôes sobre os foraminiferos e suas relações ambicntais na regiào de Ubatuba, SP. In: CONGRESSO DA ASSOCIAÇAOO BRASIIEIRA DE ESTUDOS DO QUATERNÁRIO. 1. Resumos. Porto Alegre, ABEQUA. p. 10. preferencialmente, na sua porção oeste, defletindo ao longo da sua extensão até o seu limite oposto, onde este processo dinâmico perde intensidade.

$\mathrm{Na}$ enseada de Picinguaba, a análise de fotos aéreas mostra a incidência direta dos trens de ondas provenientes de $\mathrm{SW}$, na região interna da enseada, incidindo de forma oblíqua na praia da Fazenda, e avançando da porção NW da praia até o trecho oposto, gerando correntes de deriva litorânea.

Deve-se destacar que a incidência de ondas na praia Brava provém de SE, indicando um processo de difração, possivelmente gerado pelas illas da Pesca e Selinha. A própria conformação fisiográfica da praia e sua orientação, evidenciam este processo, além de permitir inferir que a deriva litorânea se processa de SW para NE.

\section{Distribuição Sedimentar nas Enseadas}

Porcentagem de Areia e Argila

A distribuição da porcentagem das frações areia (Fig. 7), e argila (Fig. 8) nas enseadas, mostra uma tendência geral de diminuição gradual da porcentagem de areia para o interior de ambas. $\mathrm{Na}$ enseada de Ubatumirim este fato é mais evidente.

Por outro lado, ocorrem núcleos isolados, tais como, próximo à Ponta de Ubatumirim e na região frontal às praias do Meio e Puruba, onde ocorrem sedimentos com maior porcentagem de lama (em torno de $40 \%$ ), porém os teores de argila são em tomo de $5 \%$, indicando o predomínio de silte nas frações finas.

Na porção interna da enseada, na face da ilha Redonda voltada para a linha de costa, esta tendência se inverte, ocorrendo sedimentos com mais de $90 \%$ de areia, associados à formação de um cone de sedimentação, gerado pelos processos de difração de ondas e perda de energia.

Na enseada de Picinguaba, destaca-se um núcleo sob influência das ilhas das Couves e Comprida, onde os sedimentos têm seu teor em areia diminuído gradualmente, até $21 \% \mathrm{em}$ peso. Este domínio é limitado por uma faixa francamente arenosa, que se estende a partir do canal entre a ilha Comprida e a Ponta da Cruz, para as porções centrais da enseada.

A medida em que se aproxima da linha de costa, na porção interna leste da enseada, o teor de areia diminui gradativamente. Nas proximidades da Praia da Fazenda, porém esta tendência se inverte, ocorrendo um aumento na porcentagem de areia dos sedimentos, em função da influência do aporte fluvial. 


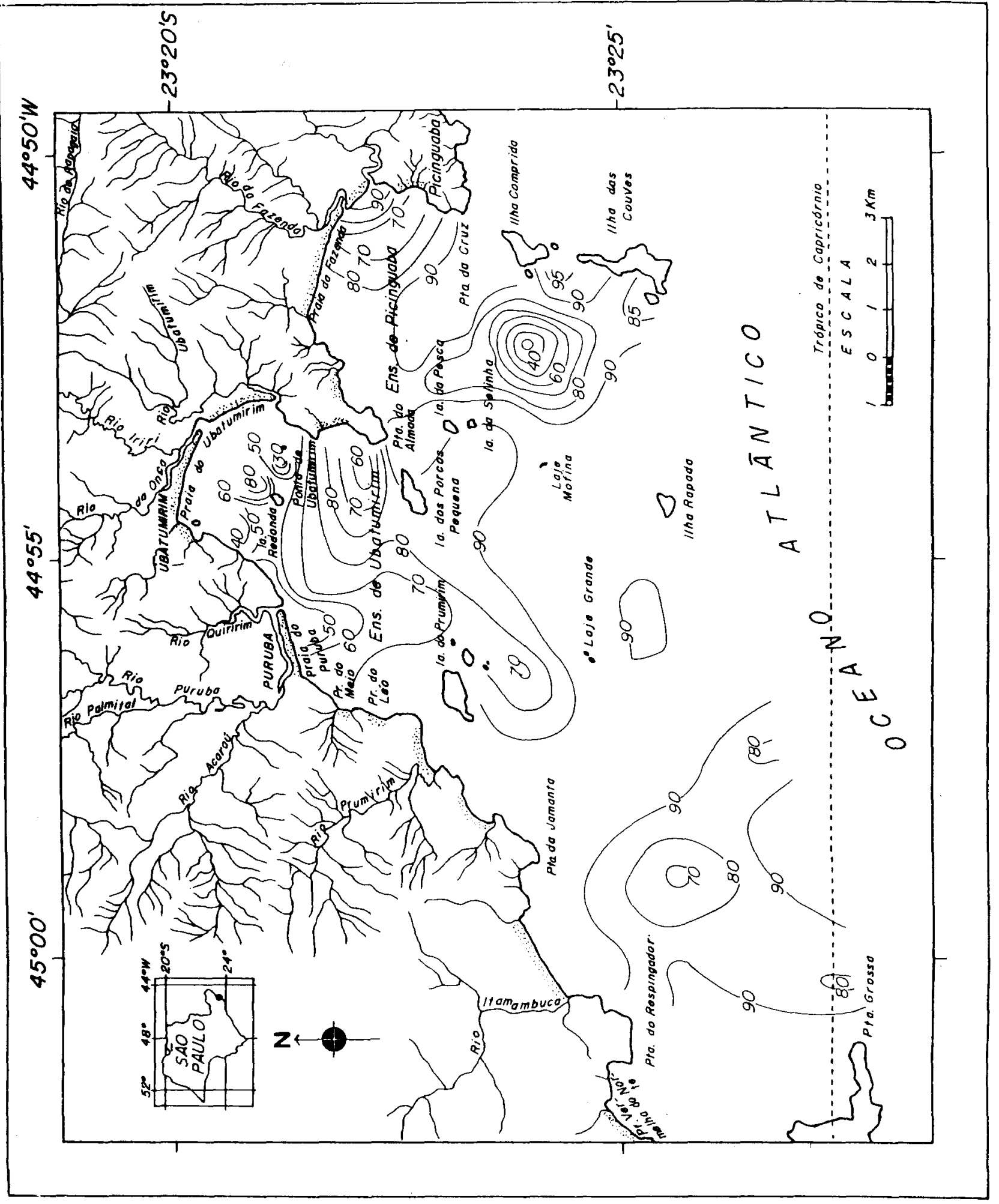

Fig. 7. Mapa de distribuição das porcentagens de areia dos sedimentos superficiais de fundo. 


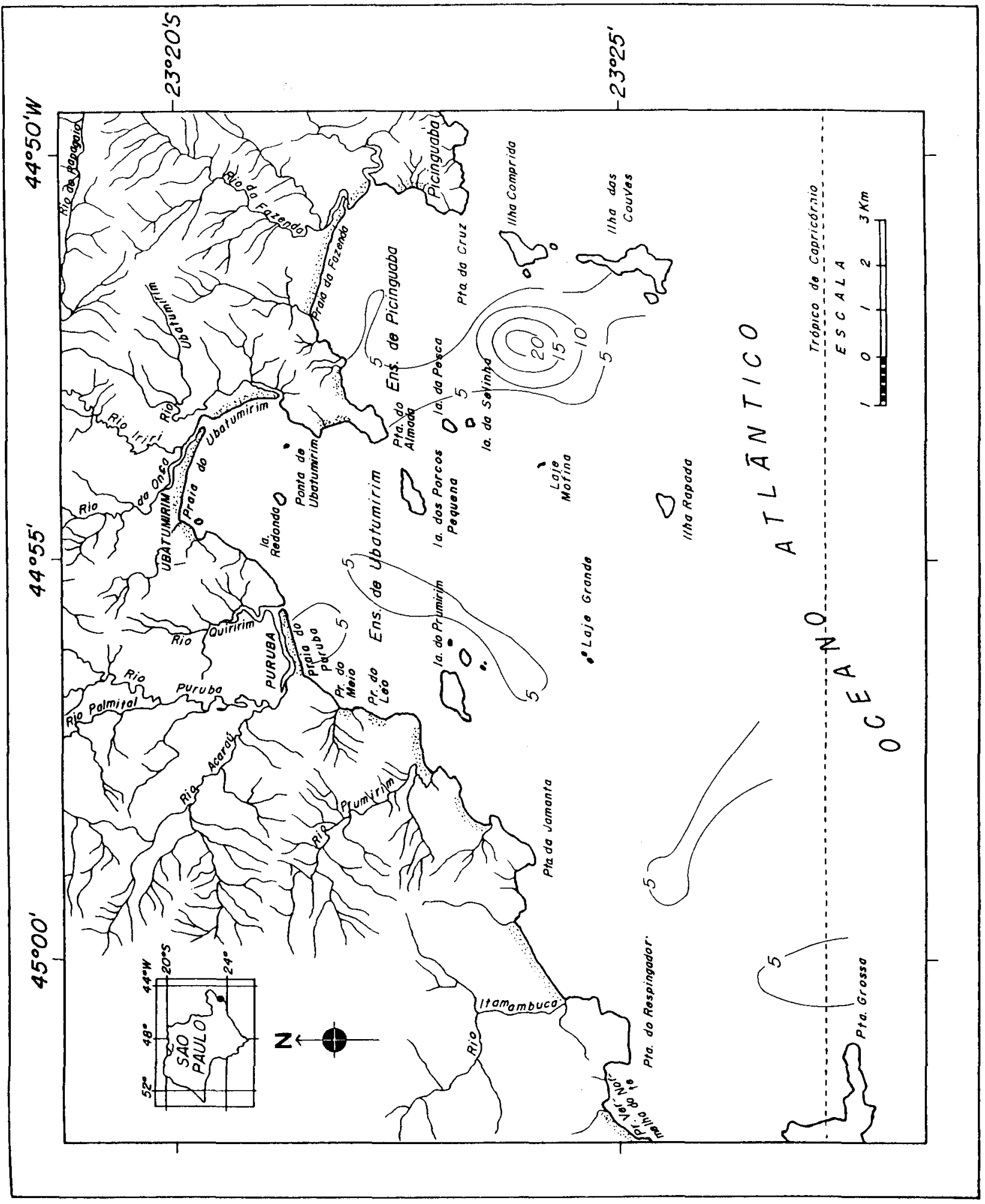

Fig. 8. Mapa de distribuição das porcentagens de argila dos sedimentos superficiais de fundo. 
Nas porções externas às enseadas, o predomínio é de sedimentos francamente arenosos, ocorrendo um núcleo com mais de $90 \%$ de areia, entre a Laje Grande e a Ilha Rapada, sendo que, apenas na área entre a ponta do Respingador e a Ponta Grossa, constata-se a ocorrência de teores menores que $80 \%$ de areia.

\section{Diâmetro médio}

A distribuição dos sedimentos, segundo o diâmetro médio (Folk \& Ward, 1957), mostrada na Figura 9 indica o predomínio de areias muito finas no interior das enseadas, principalmente na enseada de Ubatumirim. Ocorrem ainda dois núcleos de silte, um na porção central desta enseada, e outro entre a Ilha do Prumirim e a Laje Grande.

$\mathrm{Na}$ enseada de Picinguaba, a distribuição dos sedimentos apresenta-se de forma mais complexa. O predomínio é de areia muito fina, que se distribui em uma faixa que se estende dos limites interiores da enseada, na sua porção a leste e avança até a face oeste da Ilha das Couves. Ocorre ainda, nesta área, um núcleo na porção central do conjunto de ilhas da enseada, com termos gradando até silte médio.

As áreas de ocorrência de sedimentos mais grossos, correspondem à região do canal entre a Ponta da Cruz e a Ilha Comprida e áreas próximas, que se estendem numa faixa ao longo da face oeste da Itha Comprida, voltada para o interior da enseada, e atingem até a porção média do interior da mesma. Nesta área, os sedimentos apresentam diâmetros médios equivalentes a areias médias.

Outra ocorrência semelhante ocorre numa faixa estreita, em forma de língua, na porção central entre as ilhas Rapada e Couves. Esta extende-se pelo interior da enseada até próximo da laje Mofina, formando, logo a seguir, outro núcleo de sedimentos mais grossos, junto às ilhas da Selinha e Pesca, ambas compostas de areia média. O comportamento das isóbatas neste trecho, apresenta feições de canal escavado.

Há um aumento gradual no diâmetro médio dos sedimentos no sentido das porções mais externas das enseadas, com predomínio de areia fina e presença de núcleos isolados de areia média, passando para areia média com núcleos de areia grossa, sendo este o trecho onde os sedimentos apresentam diâmetro médio entre os maiores da área de estudo.

Essa distribuição ocorre de forma aproximadamente paralela à desembocadura das enseadas, e apresenta características semelhantes a uma gradação granocrescente dos sedimentos de fundo. Ocorre uma inversão desta tendência nas proximidades da região entre a Ponta do Respingador e a Ponta Grossa, com os sedimentos gradando para termos arenosos muito finos com núcleos de silte grosso.

A presença de várias ilhas e lajes distribuídas pelo interior da enseada de Picinguaba, além do canal entre a Ilha Comprida e a Ponta da Cruz, que coloca suas porções internas sob influência direta da hidrodinâmica externa incidente, the conferem uma maior complexidade nas caracteristicas sedimentares, em relação à enseada de Ubatumirim.

\section{Discussão}

As enseadas de Ubatumirim e Picinguaba. com suas desembocaduras com orientação geral para sudoeste recebem a ação direta de ondas e correntes, relacionadas à passagem de frentes frias. que representam os mecanismos mais efetivos na modelagem das características sedimentares da área.

Esses processos dinâmicos, condicionados por uma grande quantidade de ilhas e parcéis, que agem como elementos interferentes $e$ atenuantes, conferem, à área, características de grande complexidade quanto às relações de causa e efeito cntre fenômenos hidrodinâmicos e produtos sedimentares.

A dinâmica de ondas atuante na área corresponde à ação de trens de ondas gerados sob quatro condições atmosféricas distintas. Duas provenientes de S-SW, formadas em condições de pré-frontal e durante a passagem do sistema, uma oriunda de E-NE, incidente em periodos de pósfrontal, e por fim, ondas de NE, associadas aos ventos alísios.

Os corpos de deriva, lançados da desembocadura dos rios Puruba, Ubatumirim e Fazenda, foram recuperados nas respectivas praias, em posição oposta a suas desembocaduras. Este comportamento indica um sentido de transporte de fundo para oeste, a partir do contato entre o fluxo fluvial com o padrão de circulação anti-horário do interior das enseadas. Este padrão, revelado pelos perfis de temperatura e salinidade, demonstrou ser predominante ao longo do período amostrado.

Considerando-se que o deslocamento dos derivadores de fundo seria indicativo do transporte de sedimentos de fundo, pode-se inferir que os sedimentos fluviais que aportam nas enseadas, e os transportados pela deriva litorânea, seriam deslocados, a partir das desembocaduras dos rios, para oeste. 


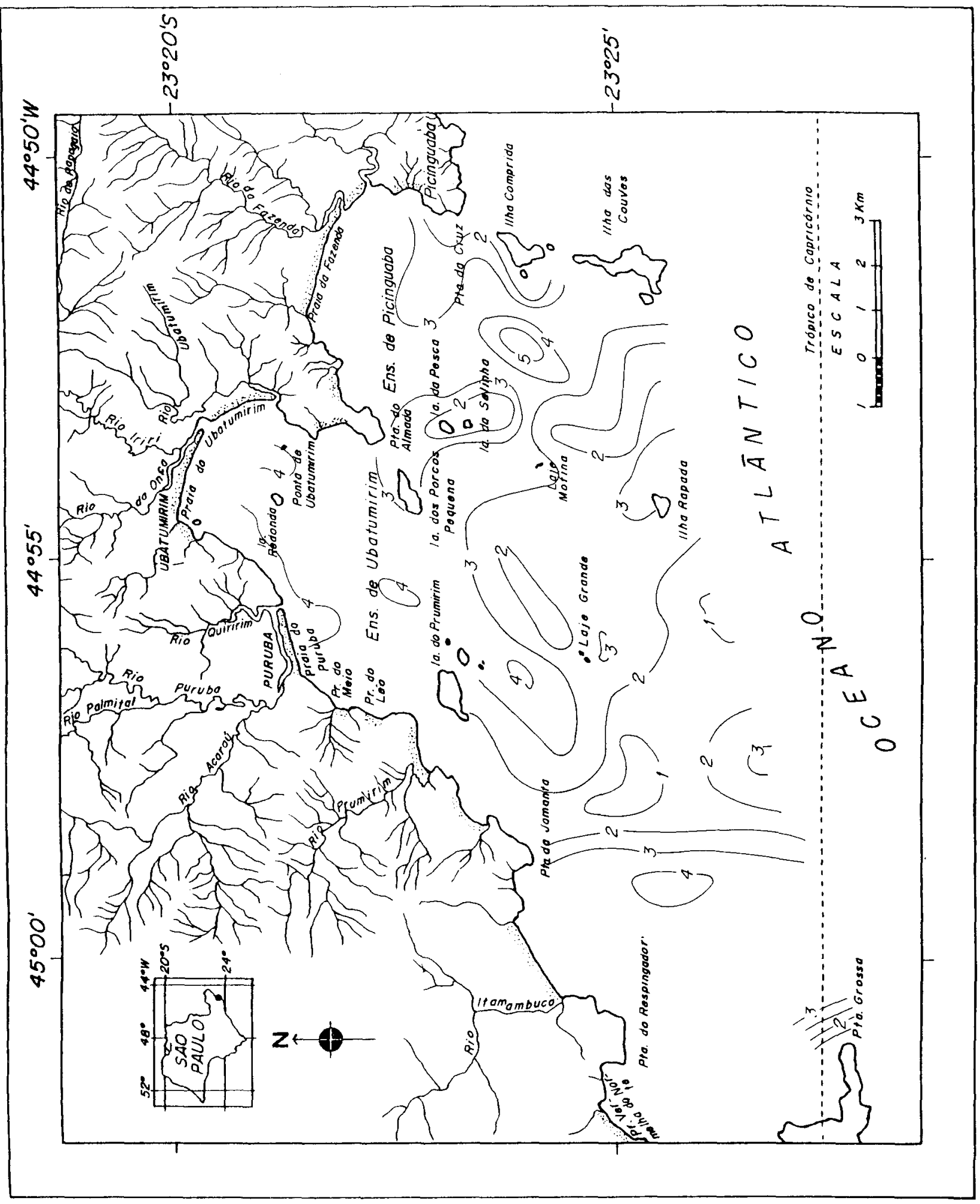

Fig. 9. Mapa de distribuição do diâmetro médio (Folk \& Ward. 1957) dos sedimentos superficiais de fundo. 
Seriam então envolvidos, em áreas rasas, por correntes geradas pelos padrões de ondas incidentes próximos à linha de costa, tomando atitude coerente com o sentido da deriva litorânea para leste, e tendendo a retornar às desembocaduras dos respectivos rios de origem. Esse fenômeno corresponderia a células de circulação internas, de sentido horário, nas proximidades da costa sendo indicativo de restrições na exportação de material terrigeno do interior das enseadas para a plataforma interna, indicando que este fenômeno ocorreria preferencialmente na forma de material em suspensão.

A área de estudo caracteriza-se como um ambiente com predomínio de sedimentação arenosa (geralmente acima de $70 \%$ ), constituída por areias finas e, subordinadamente, muito finas, com baixa porcentagem de argila (menor que 10\%). É composta por sedimentos, predominantemente, moderada a pobremente selecionados, sendo que os sedimentos da Enseada de Picinguaba apresentam tendência a uma melhor seleção.

A comparação entre os mapas de distribuição de areia e de argila mostra que as frações finas são representadas, predominantemente, por termos siltosos, ficando os termos argilosos restritos a uma única área, localizada na região abrigada da Ilha das Couves e Ilha Comprida, onde os teores são mais significativos, atingindo mais de $20 \%$ do conteúdo em peso. Pode-se considerar, também, a ausência de fontes efetivas de argilas para a região do litoral norte paulista, conforme descrito em Mahiques (1992), como resposta à presença restrita deste tipo de sedimento na área.

Essas características gerais conferem um caráter predominante de ambiente de baixo a médio grau de energia. Entretanto, as informações obtidas através da análise do comportamento das isóbatas na área, de perfis sonográficos e da observação direta por mergulho autônomo, revelaram feições de escala variada nos sedimentos presentes na área (Petti et al., 1995)*, indicando a ocorrência de agentes dinâmicos efetivos no transporte e conformação do relevo de fundo das enseadas.

A conformação e orientação NNW-SSE dessas feições de fundo indicam a influência de uma dinâmica de fundo de maior energia, possivelmente associada à passagem de sistemas frontais. A presença de registros sonográficos de padrão textural grosso e a ocorrência de areias médias nas porções

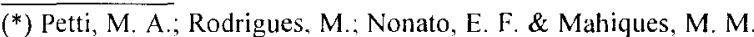
1995. Variability in the bentthic macrofauna of the coastal region of Ubatuba (São Paulo State) as a function of smal scale sedimentary features. In: LOICZ - LAND OCEAN INTERATION IN THE COASTAL ZONE SCIENTIFIC MEETING. São Paulo, 1995. Program and abstract. São Paulo, ABEQUA. p. $56-58$ externas das enseadas, sugerem, em função da ausência de fontes efetivas deste tipo sedimentar, a presença de sedimentos palimpsestos na área (Rodrigues, 1994*).

O modelo simplificado de refração e difração de trens de ondas, com base em fotografias aéreas, demonstrou que estas geram, junto à linha de costa, correntes de deriva no sentido geral leste, ao longo das praias. Este fato é marcado pela modelagem resultante da topografia de fundo do interior das enseadas, assim como, da orientação para SE dos esporões arenosos que compõem as praias do Puruba, Ubatumirim e Picinguaba.

Dentro do processo dinâmico, com o bloqueio da deriva formam-se áreas de baixa energia, nas porções orientais das enseadas, gerando áreas de deposição junto às desembocaduras dos rios, como verificado nestas porções mais confinadas.

O padrão de comportamento das isóbatas, mostra, para toda a área, uma tendência de pequenas inflexões das linhas de isóbatas, caracterizando um padrão serrilhado, com os eixos axiais das curvas orientados para NNW-SSE, com orientação e ocorrência semelhante à das feições da superfície de fundo reveladas por sonografia, segundo Rodrigues (1994). Este fato demonstra certa persistência temporal em algumas feições principais da superfície de fundo da área. Convém destacar, ainda, que as feições representativas de canais escavados com orientação aproximada NW$\mathrm{SE}$, presentes em ambas enseadas, possivelmente estão correlacionadas a paleo canais fluviais.

A integração dos elementos diversos abordados neste trabalho, permitiu o reconhecimento geral do arcabouço geológico-oceanográfico que compõe as enseadas de Ubatumirim e Picinguaba e a plataforma continental adjacente, fornecendo subsídios para a elaboração de uma carta síntese dos processos atuantes na sedimentação atual da área (Fig. 10).

\section{Conclusões}

As enseadas se caracterizaram como um ambiente de baixa energia, submetidas a processos mais enérgicos de caráter eventual. Os períodos de passagem de frentes frias influenciam diretamente o regime pluvial da área, e conseqüentemente o aporte de sedimentos continentais nas enseadas. Isto se dá

$\left(^{*}\right)$ Rodrigues, M. 1994. Caracterização preliminar da sedimentação atual das enseadas de Ubatumirim e Picinguaba, região de Ubatuba, estado de São Paulo. In: CONGRESSO BRASILEIRO DE GEOLOGIA, 38. Camboriú, 1994. Resumos expandidos. Camboriú, ABEQUA. p.394-395. 


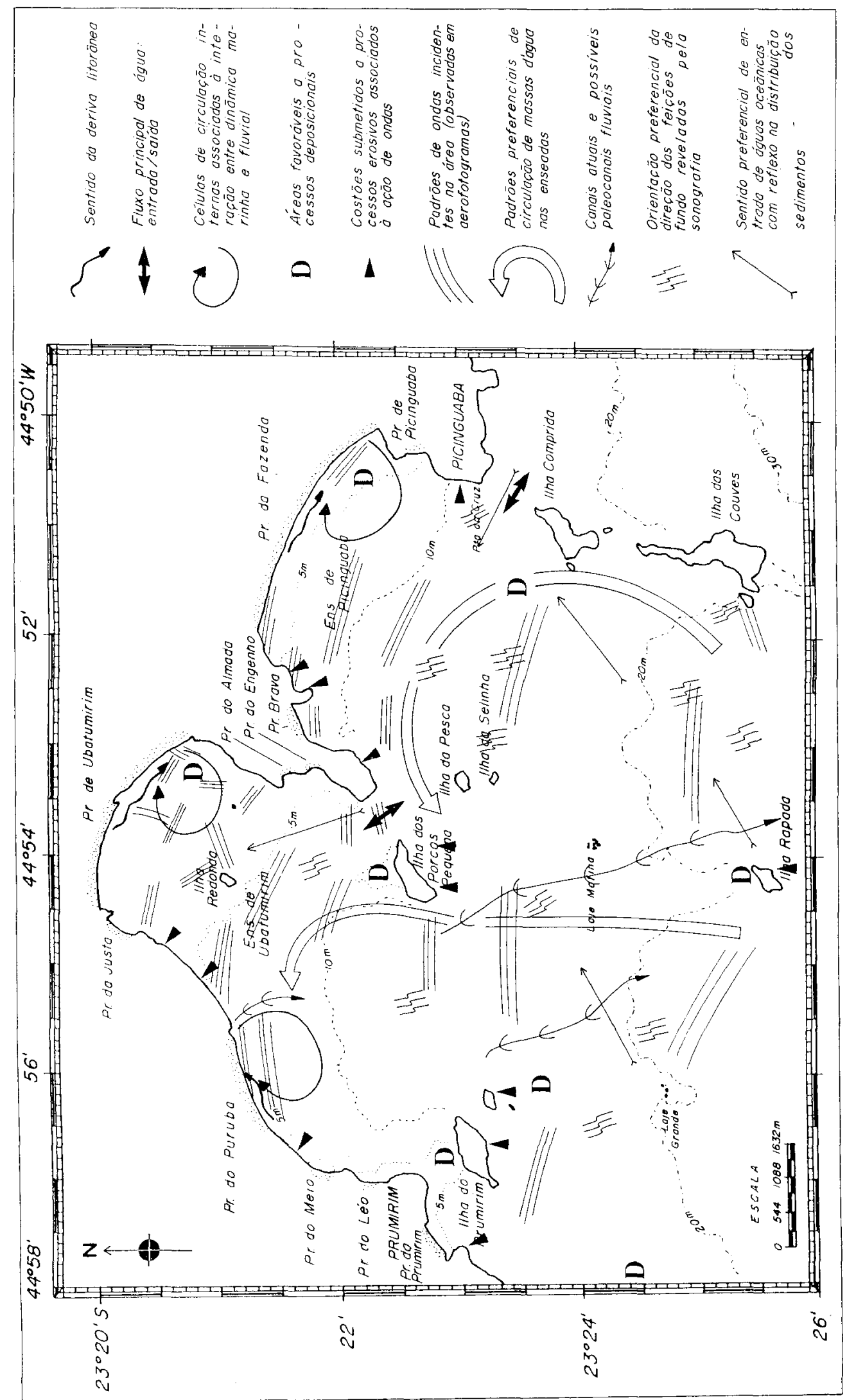

Fig. 10. Carta sintese dos processo atuantes na sedimentação atual nas enseadas de Ubatumirim e Picinguaba e plataforma continental interna adjacente. 
devido ao aumento na competência dos rios e, eventualmente a escorregamentos nas encostas $\mathrm{da}$ Serra, nesses periodos de maior freqüência e intensidade pluviométrica.

Os perfis bimestrais de termossalinidade mostram o predomínio de condições de circulação de águas oceânicas, dentro das enseadas, com sentido anti-horário, sendo que, nas porções próximas à linha de costa, os derivadores de fundo lançados da desembocadura dos rios Puruba, Ubatumirim e Fazenda, e recuperados no extremo oposto e nas porções médias das respectivas praias, teriam este comportamento induzidos pelo contato entre o fluxo fluvial com o padrão de circulação de águas oceânicas de sentido anti-horário, que deslocaria a sua trajetória para as regiões opostas às desembocaduras, onde, sob o domínio da ação de ondas sobre o fundo marinho, seria carreado até a praia, caracterizando a existência de células de circulação internas nas enseadas, associadas à desembocadura fluvial. Este processo dificulta a exportação de sedimentos continentais junto ao fundo para fora das enseadas, sendo que a saída de material ocorre essencialmente em suspensão.

A ocorrência de sedimentos compostos predominantemente por frações granulométricas média a grossa em um ambiente onde predominam areias finas a muito finas, podem estar relacionados a sedimentos relíquias retrabalhados, que ocorreriam próximos á isóbata de 25 metros, e poderiam estar associados a feições formadas em condições de nível médio do mar mais baixo que o atual, conforme descrito em Corrêa et al. (1996) para o litoral do Rio Grande do Sul.

A caracterização da dinâmica sedimentar atual, da área de estudo, demonstrou a necessidade de estudos de detalhes, em escalas cada vez mais precisas, devido a grande heterogeneidade, tanto do comportamento hidrodinâmico como da resposta sedimentar, em ambientes costeiros.

Em função da condição de baixo impacto ambiental na área, à realização deste trabalho permitiu o conhecimento da estrutura geológicooceanográfica das enseadas e o estabelecimento de uma base para estudos posteriores. Este conhecimento pode auxiliar em avaliações que envolvam instalações de obras de engenharia, estudos de impacto sobre o ecossistema, e estudos comparativos em áreas inclusas dentro deste tipo de ambiente, cuja ação antrópica já tenha modificado sensivelmente o meio.

\section{Agradecimentos}

Meus sinceros agradecimentos aos Professores Doutores Valdenir Veronese Furtado,
Edmundo Ferraz Nonato e Beatriz Beck Eichler pela inestimável contribuição para a realização deste trabalho. Agradeço ainda aos colegas do Grupo de Oceanografia Geológica do Departamento de Oceanografia Física, aos membros da tripulação do Barco Veliger II, a Sra. Marta Stephan pelas ilustrações e à Fundação de Amparo à Pesquisa do Estado de São Paulo (FAPESP) - Processos Fapesp $11^{\circ}$ 92/4990 e 93/01452-7.

\section{Referências bibliográficas}

Bartolini, C. \& Pranzini, E. 1977. Tracing nearshore bottom currents with sea-bed drifters. Mar. Geol., 23(4):275-284.

Castro Filho, B. M. de; Miranda, L. B. de \& Miyao, S. Y. 1987. Condições hidrográficas na plataforma continental ao largo de Ubatuba: variações sazonais e em média escala. Bolm Inst. oceanogr., S Paulo, 35(2):135-151.

Corrêa, I. C. S.; Martins, L .R. S.; Ketzer, J. M. M.; Elias, A. R. D. \& Martins, R. 1996. Evolução sedimentológica e paleogeográfica da plataforma continental sul e sudeste do Brasil. Notas Técnicas, CECO/UFRGS, 9:51-61.

Folk, R. L. \& Ward, W. C. 1957. Brazos River bar: a study in the significance of grain size parameters. J. sedim. Petrology, 27(1):3-27.

Magliocca, A. \& Kutner, A. S. 1965. Sedimentos de fundo da enseada do Flamengo, Ubatuba. Contrções Inst. oceanogr. Univ. S Paulo, sér. Ocean. fís., (8): 1-15.

Mahiques, M. M. de 1992. Variações temporais na sedimentação quaternária dos embaiamentos da região de Ubatuba, Estado de São Paulo. PhD Thesis. Universidade de São Paulo, Instituto Oceanográfico. 2 vol.

Mahiques, M. M. de 1995. Dinâmica sedimentar atual nas enseadas da região de Ubatuba, Estado de São Paulo. Bolm Inst. oceanogr., S Paulo, 43(2):101-110.

Mahiques, M. M. de; Tessler, M. G. \& Furtado, V. V. 1998. Characterization of energy gradient in enclosed bays of Ubatuba region, South-eastem Brazil. Estuar. coast. Shelf Sci., (47):431-446.

Occhipinti, A. G. 1963. Climatologia dinâmica do litoral sul brasileiro. Contrções Inst. Oceanogr. Univ. S Paulo, sér. Ocean. fís., (3):1-86. 
Ponçano, W. L.; Carneiro. C. D. R.; Bistrichi, C. A.; Almeida, F. F. M. \& Prandini, F. L. 1981. Mapa geomorfológico do Estado de São Paulo. São Paulo, Instituto de Pesquisas Tecnológicas. 2 vol.

Suguio, K. 1973. Introdução a sedimentologia. São Paulo, Edgard Blucher/EDUSP. 317 p.
Tessler, M. G. 1988. Dinâmica sedimentar quaternária no litoral sul-paulista. Phd Thesis. Universidade de São Paulo, Instituto de Geociências. 276p.

(Manuscrito recebido 28 novembro 2001; revisado 12 abril 2002; aceito 22 agosto 2002) 